\title{
Do Risk Premia Protect from Banking Crises?*
}

\author{
Hans Gersbach \\ Department of Economics and CEPR \\ University of Heidelberg \\ Grabengasse 14 \\ D-69117 Heidelberg, Germany \\ gersbach@uni-hd.de
}

\author{
Jan Wenzelburger \\ Department of Economics \\ University of Bielefeld \\ P.O. Box 100131 \\ D-33501 Bielefeld, Germany \\ jwenzelb@wiwi.uni-bielefeld.de
}

July 12, 2004

\begin{abstract}
This paper studies the question to what extent premia for macroeconomic risks in banking are sufficient to avoid banking crises. We investigate a competitive banking system embedded in an overlapping generation model subject to repeated macroeconomic shocks. We show that even if banks fully incorporate macroeconomic risks in their pricing of loans, a banking system may enter bankruptcy with a probability of one. A major cause for this default is that risk premia of a competitive banking system may become too small if the capital base is low.
\end{abstract}

Keywords: Financial intermediation, macroeconomic risks, banking crises, risk premia, banking regulation.

JEL Classification: D41, E4, G2.

First version: Sep. 2003, this version: July 2004.

${ }^{*}$ We would like to thank Alex Cukierman, Volker Böhm, Leo Kaas, Jean-Charles Rochet, Gilles Saint-Paul, Rune Stenbacka, Eva Terberger-Stoy, Jean Tirole, participants of seminars in Bielefeld, Frankfurt, Helsinki and Toulouse and participants at the conference of Dynamic Macroeconomics in Copenhagen 2004 for valuable comments and suggestions. 


\section{Introduction}

Severe banking crises are ubiquitous in our times. A banking crisis occurs when a large number of banks fail to meet regulatory capital requirements or are even illiquid or insolvent. The causes of most banking crises can be attributed to negative macroeconomic shocks, including their amplification mechanisms. The crises in Latin America of the 1980s and early 1990s, in East Asia later that decade, and the more prolonged stagnation in Japan, for example, were to a large extent caused by negative macroeconomic events, cf. Borio (2003). The devastating effects of banking crises on economies, including budgetary consequences of possible government bail-outs, has brought the problem of optimal policy design to the top of the international policy agenda.

Any design of policies in banking and managing banking crises must start from the fundamental question to what extent a banking system is capable of protecting itself against macroeconomic risks and thus against financial instabilities. The widespread occurrence of banking crises suggests that this protection might be generally too weak. However, it is conceptually unclear why this is the case. This paper addresses this fundamental question from a macroeconomic perspective and suggests an answer.

We study a dynamic general equilibrium model with overlapping generations in which financial intermediaries solve agency problems between saving agents and investing entrepreneurs. In each period, the repayment of entrepreneurs is subject to macroeconomic shocks. We assume that the banking system is competitive. Free exit and free entry ensure that return on bank capital is equal to alternative investment opportunities. Free exit and entry determine the price for macroeconomic risks, which is reflected by the risk premium of loans.

After establishing the existence of equilibria with financial intermediation, our paper provides two insights into a competitive banking system's vulnerability to macroeconomic shocks. First, banks charge premia for macroeconomic risks that depend on the capital base. In particular, when the capital base of the banking system is small, risk premia also become small. At the limit when bank capital is zero, the risk premium vanishes. As a consequence, a banking system with low capital is more vulnerable to a further decline of capital than a system with high capital. 
Second, if aggregate equity is below a critical level, the banking system will default with certainty in finite time. The reason for this is a vicious circle. Repeated negative macroeconomic shocks lower the equity of banks. As risk premia decrease, the likelihood of further declines of bank capital increases. This acceleration of a downward spiral in bank capital constitutes the essence of our finding that the banking system will default. In Gersbach \& Wenzelburger (2003), we have shown numerically that bank defaults in such models are costly in terms of GDP and can lead to long-lasting economic downturns. Hence, defaults in a banking system are a bad event from a macroeconomic point of view. Indeed, most sources in the literature have shown that the costs of actual banking crises may become very high (see e.g., Lindren, Gracia \& Saal (1996), Caprio \& Klingebiel (1997), and Caprio \& Honohan 1999). Our model suggests that such crises are not a low-probability event. ${ }^{1}$

The results of the paper can be applied in different ways. In a first step we may justify governmental intervention in banking, as otherwise competitive banking systems are prone to default. Our results are thus directly linked to the literature on bank competition and banking regulation. ${ }^{2}$ The theoretical literature on banking is primarily concerned with the microeconomic analysis of individual institutions and incentive problems. Models able to address intervention policies from a macroeconomic and from a system viewpoint are rare. An exception is Blum \& Hellwig (1995), who emphasize the macroeconomic importance of capital-adequacy rules by showing that strict enforcement of capital-adequacy rules in critical states may cause a socially harmful decline in aggregate bank loans. Moreover, Hellwig (1998) has raised a variety of important issues when a macroeconomic perspective on banking and risk is taken. Our analysis suggests that banking systems cannot protect themselves against defaults. In this respect, we provide a macroeconomic argument, stating why banking systems should be better protected against macroeconomic risks.

Our results may, however, may be interpreted in a different way. The vicious circle of

\footnotetext{
${ }^{1}$ There is an emerging body of literature that relates different types of crises, such as banking crises with debt crises, currency crises, and asset market crashes, and suggests remedies to reduce financial instability. See, for instance, Bernanke (1983), Mishkin (1996), Kaminsky \& Reinhart (1998), Chang \& Velasco (1998), Sachs \& Radelet (1998), Caballero \& Krishnamurthy (1998), Rogoff (1999).

${ }^{2}$ Comprehensive surveys with different emphasis can be found in Bhattacharya \& Thakor (1993), Dewatripont \& Tirole (1994), Hellwig (1994), Freixas \& Rochet (1997) and Bhattacharya, Boot \& Thakor (1998).
} 
declining bank capital and risk premia suggests that it may be difficult to eliminate banking instabilities by regulation, as banks may default with any initial level of bank capital. Hence, managing banking crises should be an integral part of both banking regulation and macroeconomic policy. ${ }^{3}$ Our model suggests that an essential task in banking regulation might be to enforce a different approach to the pricing of macroeconomic risk in the banking system, which would avoid the negative relationship of risk premia and bank capital. Whether banking regulation in the form of Basel II will be able to eliminate the vicious circle described above will be an important task for future research.

Our model introduces premia for macroeconomic risks into dynamic general equilibrium frameworks with financial intermediation. It follows the tradition of business cycle models with financial intermediation initiated by Uhlig (1995) and continued by Gersbach \& Wenzelburger (2001) (see also Williamson (1987)). Our most important innovation in this paper is a dynamic macroeconomic model of banking where free entry and exit determine premia for aggregate risk.

The paper follows the literature on how credit constraints interact with aggregate economic activity. Starting from the seminal work of Bernanke \& Gertler (1983), Greenwald \& Stiglitz (1993), Kiyotaki \& Moore (1997) and Matsuyama (2004), the literature has examined dynamic general equilibrium models in which informational frictions in capital markets cause temporary shocks to technology, thus generating large and persistent fluctuations in output and asset prices. However, none of these models contain a financial intermediation sector with balance sheet of its own, so the problem of a banking crisis does not occur in this literature.

The paper is organized as follows. In the next section, we introduce the model. In Section 3, we discuss the intermediation problem. In Section 4, we establish the existence of temporary equilibria with financial intermediation. In Section 5 we set up a random dynamical system governing the evolution of bank capital. In Section 6 we analyze the relationship between default probabilities and risk premia, and in Section 7 the default risks of the banking system.

\footnotetext{
${ }^{3} \mathrm{~A}$ macroeconomic perspective of such policy measures are described e.g. in Gersbach \& Wenzelburger (2003).
} 


\section{Model}

We consider an overlapping generations model with financial intermediation, in which agents live for two periods. Time is infinite in the forward direction and divided into discrete periods indexed by $t$. There is one physical good that can be used for consumption or investment. Each generation consists of a continuum of agents with two-period lives, indexed by $[0,1]$. Each individual of each generation receives an endowment $e$ of goods when young and none when old. The endowment may be thought of as being obtained from short-term production with inelastically supplied labor. Generations are divided into two classes. A fraction $\eta$ of the individuals are potential entrepreneurs, the rest $1-\eta$ of the population are consumers. Potential entrepreneurs and consumers differ in that only the former have access to investment projects.

Consumers are endowed with preferences over consumption in the two periods of their lives. Let $u\left(c_{t}^{1}, c_{t}^{2}\right)$ be a standard intertemporal utility function of a consumer, with $c_{t}^{1}, c_{t}^{2}$ denoting youthful and old-age consumption respectively of a consumer born in period $t .^{4}$ Given an endowment $e$ when young and a deposit interest rate $r^{d}$, each young household saves the amount $s\left(r^{d}\right)$. Aggregate savings of all households is then $S\left(r^{d}\right)=(1-\eta) s\left(r^{d}\right)$.

Each entrepreneur has access to a production project that converts period- $t$ goods into period- $t+1$ goods. For simplicity, we assume that potential entrepreneurs are risk neutral and consume only when old. $e+I$ are the funds required for an investment project. An entrepreneur must borrow $I$ units of the goods in order to undertake the investment project. The entrepreneurs are heterogeneous and indexed by a quality parameter $i$ which is uniformly distributed on $[0, \eta]$. If an entrepreneur of type $i$ obtains additional resources $I$ and decides to invest, his investment returns in the next period amount to

$$
f_{i}(q, e+I)=(1+i) q f(e+I)
$$

where $f$ denotes a standard atemporal neoclassical production function. The parameter $q \in \mathbb{R}_{+}$is subject to exogenous stochastic noise governed by an iid process on a compact interval $[\underline{q}, \bar{q}]$.

\footnotetext{
${ }^{4}$ In view of the applications, it is straightforward to replace the OG structure by infinitely living agents who optimize myopically.
} 
There are $n(n>1)$ identical banks, indexed by $j=1, \ldots, n$, owned by entrepreneurs. Banks finance entrepreneurs and maximize profits accruing to current shareholders. Transfer of ownership of banks to the next generation occurs through bequests. We assume that the number of banks is large and that the banking industry is perfectly competitive, i.e., banks take deposit and loan rates as given. Moreover, banks freely decide whether or not to offer their intermediation services. This polar assumption is made on purpose since we want to examine to what extent a perfectly competitive banking system with free entry and exit is vulnerable to banking crises.

Each bank $j$ can sign deposit contracts $D\left(r^{d}\right)$, where $1+r^{d}$ is the repayment offered for 1 unit of resources. Loan contracts of bank $j$ are denoted by $C\left(r^{c}\right)$, while $1+r^{c}$ is the repayment required from entrepreneurs for 1 unit of funds. All deposits and loan contracts last for one period. Banks act as delegated monitors as depositors cannot observe the quality of investment projects and whether entrepreneurs invest or consume their funds. Banks are assumed to be able to secure both investment by entrepreneurs, who have obtained a loan, and the liquidation value in case of default. There are various ways to formulate moral hazard and monitoring technologies justifying this assumption. Such detailed justifications for the current model set-up are provided in Gersbach \& Uhlig (2004) and Gersbach \& Wenzelburger (2001).

\section{Financial intermediation}

\subsection{Sequence of events}

We introduce intermediation that takes place in each period. We drop the time index in this section. The time-line of actions in the economy within a typical period $t$ is as follows:

1. Old entrepreneurs pay back with limited liability. The current deficits or reserves are determined. Reserves are distributed among shareholders according to payout rules.

2. Given $r^{d}$ and $r^{c}$, banks decide whether to exit and to save their reserves. If they stay in business, they offer their intermediation services. 
3. Consumers and entrepreneurs decide which contracts to accept. Resources are exchanged and banks pay back old depositors.

4. Young entrepreneurs produce subject to a macroeconomic shock.

In order to simplify the exposition, we set the costs of intermediation to zero. ${ }^{5}$ We make the following assumptions regarding the behavior of banks. Banks operate under limited liability. Depositors randomly choose a bank that offers its intermediation services in order to save. Similarly, entrepreneurs applying for a loan contract choose banks randomly. Throughout the paper we assume that aggregate uncertainty is canceled out when depositors and entrepreneurs randomly choose banks. That is, each active bank obtains the same amount of deposits and loans. ${ }^{6}$ Loans are constrained by the amount of deposits obtained. If entrepreneurs applying for loans were rejected, they will randomly choose a bank and save.

Finally, banks can exit completely, but cannot partially reduce their equity while still offering their intermediation services. The assumption can be justified in several ways. First, it could be derived as an equilibrium phenomenon when banks are allowed to reduce their equity. For instance, consumers, upon observing the levels of equity, may decide to deposit their resources only at banks that have the highest level of equity because those banks have the lowest default probability. In such cases, banks will not reduce equity. Second, banks that offer their services are required by regulation to hold a certain amount of equity. Basel I and in the future Basel II are regulatory frameworks that stipulate such capital requirements for banks. Third, reducing equity may harm the efficiency of the monitoring function of a bank and thus may create losses which may make the reduction unprofitable.

Entrepreneurs are price takers and operate under limited liability. Under the norationing assumption, all entrepreneurs applying for a loan contract randomly choose a bank that offers intermediation services. Given a loan interest rate $r^{c}$, the expected

\footnotetext{
${ }^{5}$ Such costs would include monitoring expenses of banks. If intermediation costs are a fixed amount per loan, the equilibrium value of the spread $r^{c}-r^{d}$ in all of our results would increase accordingly.

${ }^{6}$ The exact construction of individual randomness so that this statement holds can be found in Alos-Ferrer (1999). We could also rely on the weaker forms of the strong law of large numbers developed in Uhlig (1996) and Al-Najjar (1996), where independence of individual random variables can be assumed and aggregate stability is the limit of an economy with finite characteristics.
} 
profit of an investing entrepreneur $i$ is

$$
\Pi\left(i, r^{c}\right):=\int_{\mathbb{R}_{+}} \max \left\{(1+i) q f(e+I)-I\left(1+r^{c}\right), 0\right\} \mu(d q),
$$

where $\mu$ denotes the probability distribution of the shocks. Note that $\Pi\left(i, r^{c}\right)$ is monotonically increasing in quality levels $i$ and monotonically decreasing in loan rates $r^{c}$. To obtain a loan contract of size $I$, entrepreneurs are required to invest all of their equity $e$. They face a binary decision problem, such that a risk-neutral entrepreneur with quality parameter $i \in[0, \eta]$ will invest, if

$$
\Pi\left(i, r^{c}\right) \geq e\left(1+r^{d}\right)
$$

Banks do not have to fear low-quality entrepreneurs applying for loans as they are always better off with saving endowments. Moreover, banks are able to secure repayments.

\section{$3.2 \quad$ Temporary equilibria}

In order to derive the intermediation equilibrium, we assume that banks are bailed out and deposits are ensured. Obviously, the feasibility of bail-outs must be checked for all possible scenarios. To this end, we assume that savings are never sufficient to fund all entrepreneurs, so that

$$
S\left(r^{d}\right)=(1-\eta) s\left(r^{d}\right)<\eta I \text { for all } r^{d} \geq 0 .
$$

Let $d$ denote the current capital base of the banking system. An individual bank has an amount of equity of $d_{j}=$ fracdn. As all banks are assumed to be identical we will formulate the equilibrium conditions for the whole banking system and hence we will focus directly on the evolution of the aggregate bank capital $d$.

There are two boundary values for $d$. Let $S_{\max }:=\max \left\{S\left(r^{d}\right): r^{d} \geq 0\right\}$ denote maximal aggregate savings and set $\bar{d}:=\eta I-S_{\max }>0$ for an upper bound for the capital bases. If $d>\bar{d}$, we assume that banks pay excess reserves to bank owners according to pay-out rules. On the other hand, if $d \leq 0$, then the capital base of the banking system has vanished, causing a default of the system. 
For these reasons, the intermediation problem arises only when $d \in(0, \bar{d}]$. For each $d \in(d, \bar{d}]$ and each $r^{d} \geq 0$ there exists a unique critical entrepreneur $i_{G} \in[0, \eta]$, given by

$$
i_{G}=i_{G}\left(d, r^{d}\right):=\frac{\eta I-S\left(r^{d}\right)-d}{e+I}
$$

such that savings are balanced by investments, that is,

$$
S\left(r^{d}\right)+e i_{G}\left(d, r^{d}\right)+d=\left[\eta-i_{G}\left(d, r^{d}\right)\right] I, \quad d \in(0, \bar{d}] .
$$

Let $d \in(0, \bar{d}]$ be the current level of reserves (deficits) at the beginning of an arbitrary period. Banks raise funds $S\left(r^{d}\right)+e i_{G}\left(d, r^{d}\right)$ that have to be payed back with interest at the end of the subsequent period. In a competitive equilibrium, these funds will have to satisfy (3).

Banks lend $\left[\eta-i_{G}\right] I$ to firms and will receive payments $P=P\left(i_{G}, q, r^{c}\right)$ at the end of the period, given by

$$
P\left(i_{G}, q, r^{c}\right)=\int_{i_{G}}^{\eta} \min \left\{(1+i) q f(e+I), I\left(1+r^{c}\right)\right\} d i
$$

where $i_{G}=i_{G}\left(d, r^{d}\right)$. Given a pair of interest rates $r^{d}, r^{c}$, the balance sheet of the banking system is given by a function $G\left(\cdot, q, r^{d}, r^{c}\right):(0, \bar{d}] \rightarrow \mathbb{R}$, defined by

$$
G\left(d, q, r^{d}, r^{c}\right)=P\left(i_{G}\left(d, r^{d}\right), q, r^{c}\right)-\left[S\left(r^{d}\right)+e i_{G}\left(d, r^{d}\right)\right]\left(1+r^{d}\right),
$$

such that for each shock shock $q$ and each $r^{c}, r^{d} \geq 0, G\left(d, q, r^{d}, r^{c}\right)$ is the capital base of the banking system at the end of the period.

Suppose $d>0$. A temporary equilibrium with financial intermediation in a particular period is a pair of interest rates $\left(r_{*}^{d}, r_{*}^{c}\right)$ such that

(i) loan demand equals loan supply;

(ii) no bank exits and no bank enters the market;

(iii) firms take optimal investment and saving decisions.

Writing

$$
G^{+}\left(d, q, r^{d}, r^{c}\right)=\max \left\{G\left(d, q, r^{d}, r^{c}\right), 0\right\}
$$


the expected profit of banks for interest rates $r^{c}, r^{d}$ which operate under limited liability is $\mathbb{E}\left[G^{+}\left(d, q, r^{d}, r^{c}\right)\right]$. More formally, a temporary equilibrium with financial intermediation is defined as follows.

\section{Definition 1}

Let $d \in(0, \bar{d}]$ denote the capital base of the banking system operating under limited liability. A temporary equilibrium with financial intermediation (TEFI) is a pair of interest rates $\left(r_{*}^{d}, r_{*}^{c}\right)$ such that the following conditions hold:

$$
\begin{aligned}
\mathbb{E}\left[G^{+}\left(d, \cdot, r_{*}^{d}, r_{*}^{c}\right)\right] & =d\left(1+r_{*}^{d}\right) \\
\Pi\left(i_{G}\left(d, r_{*}^{d}\right), r_{*}^{c}\right) & =e\left(1+r_{*}^{d}\right) \\
S\left(r_{*}^{d}\right)+e i_{G}\left(d, r_{*}^{d}\right)+d & =\left[\eta-i_{G}\left(d, r_{*}^{d}\right)\right] I
\end{aligned}
$$

Condition (6) is the no-exit and no-entry condition for banks. Of course, the condition has to be applied to an individual bank. As the condition for an individual bank is obtained by dividing both sides in equation (6) through the number of banks, it is convenient to work directly with the aggregate condition as we will do throughout the paper.

Condition (7) states that all entrepreneurs $i \geq i_{G}\left(d, r_{*}^{d}\right)$ invest, while all entrepreneurs $i<i_{G}\left(d, r_{*}^{d}\right)$ save. The spread $r_{*}^{c}-r_{*}^{d}$ represents the premium banks obtain for bearing macroeconomic risks. For the sake of completeness the definition of TEFI includes (8), stating that aggregate demand for loans $\left[\eta-i_{G}\left(d, r_{*}^{d}\right)\right] I$ is balanced by loan supply on the left hand side of equation (8).

Condition (8) determines the critical investing entrepreneur $i_{G}\left(d, r_{*}^{d}\right)$ independently of equilibrium loan interest rates. Assuming that aggregate saving $S\left(r^{d}\right)$ is increasing in $r^{d}$, we see that $i_{G}$ is decreasing in $d$ and $r^{d}$. In both cases more resources are available which induce entrepreneurs with lower quality levels to invest. This is the case despite the fact that saving endowments becomes more attractive for increasing deposit interest rates $r^{d}$.

The temporary equilibrium notion of Definition 1 assumes that banks operate under limited liability. This is a standard assumption when bank managers act in the interest of equity holders. However, it is also conceivable that banks (or their managers) 
internalize negative realizations of equity. This may happen, for instance, if bank managers suffer non-pecuniary punishments such as a loss of reputation or a loss of career opportunities when they default. Or bank managers may be punished by regulators as soon as their equity becomes negative. It is straightforward to define a temporary equilibrium notion for a banking system with full liability by modifying the no-entry condition (6) to

$$
\mathbb{E}\left[G\left(d, \cdot, r_{*}^{d}, r_{*}^{c}\right)\right]=d\left(1+r_{*}^{d}\right)
$$

\section{Existence of temporary equilibria}

In this section we establish the existence of temporary equilibria with financial intermediation. Assume for the remainder of the paper that the productivity of the entrepreneur with quality level $\frac{\eta}{2}$ is on average greater than unity, that is,

$$
\frac{\left(1+\frac{\eta}{2}\right) \mathbb{E}[q] f(e+I)}{I}>1
$$

We now obtain the desired existence result.

\section{Theorem 1}

Consider a competitive banking system operating under limited liability. Let the following conditions be satisfied:

(i) The productivity of the entrepreneur with quality level $\frac{\eta}{2}$ is on average greater than unity and there exists an interest rate $\bar{r}^{d}$ with

$$
0<\bar{r}^{d}<\frac{\left(1+\frac{\eta}{2}\right) \mathbb{E}[q] f(e+I)}{I},
$$

such that $\Pi(0,0)>e\left(1+\bar{r}^{d}\right)>\Pi\left(\eta, \bar{r}^{d}\right)$.

(ii) Aggregate saving $S\left(r^{d}\right)$ is non-decreasing in $r^{d}$ and

$$
S\left(r^{d}\right)+\eta e>\left(1+r^{d}\right) S^{\prime}\left(r^{d}\right) \text { for all } 0 \leq r^{d} \leq \bar{r}^{d} .
$$

(iii) Let $r_{0}^{c}>0$ denote the loan interest rate with $\Pi\left(0, r_{0}^{c}\right)=e$, such that the entrepreneur with the lowest quality level $i=0$ will invest for $r^{d}=0$. Assume that average repayments to banks are sufficiently high, so that

$$
\frac{\mathbb{E}\left[P\left(0, \cdot, r_{0}^{c}\right)\right]}{\eta I} \geq 1
$$


Then for each $d \in(0, \bar{d}]$ there exists a unique temporary equilibrium with financial intermediation (TEFI), given by the interest rates $\left(r_{*}^{d}(d), r_{*}^{c}(d)\right) \in\left[0, r_{U B}^{d}\right] \times\left[r_{L B}^{c}, r_{U B}^{c}\right]$. The lower and upper bound $r_{L B}^{c}>0, r_{U B}^{d}$, and $r_{U B}^{c}$ are defined by

$$
\Pi\left(0, r_{L B}^{c}\right)=e\left(1+r_{L B}^{c}\right), \quad \Pi\left(\eta, r_{U B}^{d}\right)=e\left(1+r_{U B}^{d}\right), \quad \text { and } \quad \Pi\left(\eta, r_{U B}^{c}\right)=e,
$$

respectively.

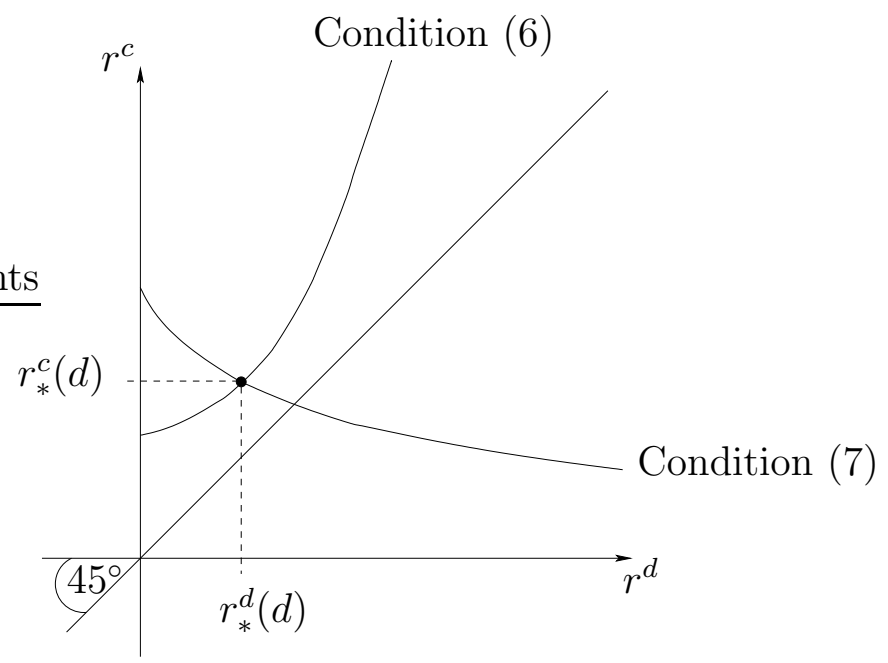

Figure 1: Existence and uniqueness of a TEFI for a given $d \in(0, \bar{d}]$.

The result of Theorem 1 the proof of which is given in the appendix is illustrated in Figure 1. For an arbitrary capital base $d \in(0, \bar{d}]$, the figures depicts interest rates satisfying the no-entry condition (6) and interest rates satisfying the indifference condition (7). A TEFI is characterized by the intersection point of these two curves. Theorem 1 is the foundation of our further analysis. Temporary equilibria exist since savings and loan supply increase with the deposit rate, while the demand for loans depends negatively on the loan rate. Observe that Condition (ii) induces an upper bound for the savings elasticity of consumers, which is automatically satisfied for an inelastic savings function as well as for a savings function with elasticities less than unity. By setting an appropriate spread $r_{*}^{c}-r_{*}^{d}$ banks earn returns on equity which are high enough to ensure that there is no incentive to exit. It is intuitively clear that risk premia must be non-negative. Formally we have: 


\section{Corollary 1}

The equilibrium deposit rate $r_{*}^{d}(d)$ is decreasing in $d \in(0, \bar{d}]$. Moreover, risk premia are non-negative such that $r_{*}^{c}(d)-r_{*}^{d}(d) \geq 0$ for all $d \in(0, \bar{d}]$.

The proof is given in the appendix. To complete our investigation of existence, we consider the case of full liability. As the next lemma shows, the existence of temporary equilibria is obtained in this case as well.

\section{Lemma 1}

Consider a banking system operating under full liability and suppose that the hypotheses of Theorem 1 are satisfied. Then for each $d \in(0, \bar{d}]$, there exists a unique temporary equilibrium with financial intermediation $\left(r_{+}^{d}(d), r_{+}^{c}(d)\right) \in\left[0, r_{U B}^{d}\right] \times\left[r_{L B}^{c}, r_{U B}^{c}\right]$, where the bounds $r_{L B}^{c}, r_{U B}^{d}$, and $r_{U B}^{c}$ are given in Theorem 1. Moreover, the interest rates satisfy

$$
r_{+}^{d}(d) \leq r_{*}^{d}(d) \quad \text { and } \quad r_{+}^{c}(d) \geq r_{*}^{c}(d)
$$

with $\left(r_{*}^{d}(d), r_{*}^{c}(d)\right)$ denoting the TEFI given in Theorem 1 .

The proof of Lemma 1 is given in the appendix. An immediate consequence of Lemma 1 is that risk premia of a competitive banking system with limited liability are lower than those of banks operating under full liability. The reason is intuitively clear. With full liability the free exit condition forces banks to make higher profits in order to cover the greater risk for potential losses. This requires higher risk premia. Since, under Lemma 1, deposit rates are lower and loan rates are higher under full liability, both depositors and entrepreneurs will have to bear the additional risk banks are exposed to under full liability.

\section{Evolution of the banking system}

In this section we describe the evolution of capital in the banking system. Adverse macroeconomic shocks may lead to bankruptcy of entrepreneurs and to low repayments to banks, thus affecting the evolution of bank capital. Let $d_{t} \in(0, \bar{d}]$ denote the capital base of the banking system at the beginning of some period $t$, where we allow the banking system to start with an arbitrary level $d_{0} \in(0, \bar{d}]$. At the beginning of period $t$, banks raise funds $S\left(r_{*}^{d}\left(d_{t}\right)\right)+e i_{G}\left(d_{t}, r_{*}^{d}\left(d_{t}\right)\right)$ that have to be paid back with interest 
at the end of that period. Writing $i_{*}\left(d_{t}\right):=i_{G}\left(d_{t}, r_{*}^{d}\left(d_{t}\right)\right)$ for the critical entrepreneur in a competitive equilibrium, these funds must satisfy

$$
S\left(r_{*}^{d}\left(d_{t}\right)\right)+e i_{*}\left(d_{t}\right)+d_{t}=I\left[\eta-i_{*}\left(d_{t}\right)\right], \quad d_{t} \in(0, \bar{d}] .
$$

The corresponding equilibrium interest rates $r_{*}^{c}\left(d_{t}\right), r_{*}^{d}\left(d_{t}\right)$ are given by Theorem 1 , such that given the shock $q_{t}$, the new level of reserves (deficits) $d_{t+1}$ is determined by

$$
d_{t+1}=\min \left\{G_{*}\left(d_{t}, q_{t}\right), \bar{d}\right\}, \quad d_{t} \in(0, \bar{d}]
$$

where the map $G_{*}$ is defined as follows. Using the definition of the balance sheet of the banking system $(5)$, for each $q$ the function $G_{\star}(\cdot, q):(0, \bar{d}] \rightarrow(-\infty, \bar{d}]$ is defined by

$$
\begin{aligned}
G_{*}(d, q) & :=G\left(d, q, r_{*}^{d}(d), r_{*}^{c}(d)\right) \\
& =P\left(i_{*}(d), q, r_{*}^{c}(d)\right)-\left[S\left(r_{*}^{d}(d)\right)+e i_{*}(d)\right]\left(1+r_{*}^{d}(d)\right)
\end{aligned}
$$

Note that we account for the fact that excess reserves above $\bar{d}$ will be distributed among old entrepreneurs only. Thus possible dividend payments will affect neither savings nor investment decisions.

The map (12) is continuous in both arguments and describes a random difference equation. Since $\left\{q_{t}\right\}_{t \in \mathbb{N}}$ is an iid process, the sequence of reserves $\left\{d_{t}\right\}_{t \in \mathbb{N}}$ generated by (12) is a Markov process. In particular, this implies that conditional expectations satisfy

$$
\mathbb{E}_{t}\left[d_{t+1}\right] \equiv \mathbb{E}\left[d_{t+1} \mid d_{t}\right]=\mathbb{E}\left[\max \left\{G_{*}\left(d_{t}, \cdot\right), \bar{d}\right\}\right], \quad t \in \mathbb{N},
$$

cf. Bauer (1991, p. 134). If $d_{t+1} \geq 0$, then all depositors have been repaid and $d_{t+1}$ represents the banks' reserves at the beginning of period $t+1$. If $d_{t+1}<0$, then the banks incur losses and $d_{t+1}$ is the amount of liabilities that could not be covered by loan repayments of entrepreneurs. In such a case the banking system has negative equity and is bankrupt.

\section{Risk premia and default probabilities}

Having established the existence of temporary equilibria, we investigate the role of risk premia in the default probability of entrepreneurs. An entrepreneur with quality level 
$i$ enters bankruptcy, if she is unable to fully pay back her credit, that is, if

$$
I\left(1+r^{c}\right)>q(1+i) f(e+I) .
$$

The entrepreneur with the lowest quality level who is not bankrupt after encountering the shock $q$ is given by

$$
i_{B}=i_{B}\left(i_{G}, r^{c}, q\right):= \begin{cases}i_{G} & \text { if } q \geq q_{\mathrm{NB}}\left(i_{G}, r^{c}\right), \\ \frac{I\left(1+r^{c}\right)}{q f}-1 & \text { if } q_{\mathrm{TB}}\left(r^{c}\right)<q<q_{\mathrm{NB}}\left(i_{G}, r^{c}\right), \\ \eta & \text { if } q \leq q_{\mathrm{TB}}\left(r^{c}\right)\end{cases}
$$

where

$$
q_{\mathrm{NB}}\left(i_{G}, r^{c}\right):=\frac{I\left(1+r^{c}\right)}{\left(1+i_{G}\right) f(e+I)} \quad \text { and } \quad q_{\mathrm{TB}}\left(r^{c}\right):=\frac{I\left(1+r^{c}\right)}{(1+\eta) f(e+I)}
$$

Observe that no entrepreneur enters bankruptcy and aggregate losses of banks are zero, if shocks are sufficiently positive, $q \geq q_{\mathrm{NB}}\left(i_{G}, r^{c}\right)$. For shocks $q_{\mathrm{TB}}\left(r^{c}\right)<q<q_{\mathrm{NB}}\left(i_{G}, r^{c}\right)$, all investing entrepreneurs with quality levels $i_{G} \leq i<i_{B}\left(i_{G}, r^{c}, q\right)$ enter bankruptcy, whereas entrepreneurs with quality levels $i \geq i_{B}\left(i_{G}, r^{c}, q\right)$ pay back their loans fully. On the other hand, all entrepreneurs enter bankruptcy if $q \leq q_{\mathrm{TB}}\left(r^{c}\right)$ and losses are maximal. Solving the integral in (4), firms' repayments $P=P\left(i_{G}, q, r^{c}\right)$ are

$$
P= \begin{cases}{\left[\eta-i_{G}\right] I\left(1+r^{c}\right)-q f(e+I) \frac{1}{2}\left[i_{B}-i_{G}\right]^{2}} & \text { if } q>q_{\mathrm{TB}}\left(r^{c}\right), \\ {\left[\eta-i_{G}\right]\left(1+\frac{1}{2}\left(\eta+i_{G}\right)\right) q f(e+I)} & \text { if } q \leq q_{\mathrm{TB}}\left(r^{c}\right) .\end{cases}
$$

implying that firms' repayments are determined by total repayments minus losses due to bankruptcies. Setting

$$
\bar{r}^{c}:=\frac{(1+\eta) \bar{q} f(e+I)}{I}-1
$$

with $\bar{q}$ denoting the highest possible shock, we see that $q_{\mathrm{TB}}\left(r^{c}\right)<\bar{q}$ whenever $r^{c}<\bar{r}^{c}$. Since $\Pi\left(i, \bar{r}^{c}\right)=0$ for all $i \in[0, \eta]$, it follows from the definition of the maximal loan interest rate in Theorem 1 that $r_{\mathrm{UB}}^{c}<\bar{r}^{c}$, such that in a TEFI, entrepreneurs with sufficiently high quality do not default with positive probability.

It is now straightforward to formalize the default probability of entrepreneurs in a TEFI. For an arbitrary capital base $d \in(0, \bar{d}]$, if $q_{\mathrm{NB}}\left(i_{*}(d), r_{*}^{c}(d)\right)>\underline{q}$, then the probability that entrepreneurs go bankrupt conditional on $d$ is

$$
\operatorname{Prob}\left(i_{B}\left(i_{*}(d), r_{*}^{c}(d), \cdot\right)>i_{*}(d)\right)=\int_{\underline{q}}^{q_{\mathrm{NB}}\left(i_{*}(d), r_{*}^{c}(d)\right)} \mu(d q) .
$$


If $q_{\mathrm{NB}}\left(i_{*}(d), r_{*}^{c}(d)\right) \leq \underline{q}$, then the probability that an entrepreneur enters bankruptcy conditional on $d$ is zero. Since $q_{\mathrm{NB}}\left(i_{*}(d), r_{*}^{c}(d)\right) \geq q_{\mathrm{NB}}\left(i_{G}(0,0), r_{L B}^{c}\right)$, the probability for bankruptcies is positive independently of the capital base if

$$
q_{\mathrm{NB}}\left(i_{G}(0,0), r_{L B}^{c}\right)>\underline{q} .
$$

In this case the entrepreneur with quality level $i_{G}(0,0)$ enters bankruptcy for shocks close to $\underline{q}$.

We are now ready to investigate how a competitive banking system incorporates macroeconomic default risks of entrepreneurs. We start with some simple observations.

\section{Proposition 1}

Let $d \in(0, \bar{d}]$ be arbitrary. Then the following holds true.

(i) If the probability for bankruptcies of entrepreneurs is zero, i.e.

$$
q_{N B}\left(i_{*}(d), r_{*}^{c}(d)\right) \leq \underline{q}
$$

then the risk premium for banks is zero, $r_{*}^{c}(d)-r_{*}^{d}(d)=0$.

(ii) If the probability for bankruptcies of entrepreneurs is strictly positive, i.e.

$$
q_{N B}\left(i_{*}(d), r_{*}^{c}(d)\right)>\underline{q},
$$

then the risk premium for banks is strictly positive, $r_{*}^{c}(d)-r_{*}^{d}(d)>0$.

Proposition 1 confirms the intuition that a competitive banking system will not charge risk premia if there is zero risk for bankruptcies of entrepreneurs because the return on equity is $r_{*}^{d}$. As soon as the probability for bankruptcies of entrepreneurs is strictly positive, Proposition 1 shows that strictly positive risk premia ensure higher profits.

For the case $q>q_{\mathrm{TB}}\left(r_{*}^{c}(d)\right)$ we can represent the evolution of bank capital in a particularly convenient way. Using the balance condition (11) and the repayments of entrepreneurs (15), we see that the map $G_{*}$ which drives the evolution of bank capital takes the form

$$
\begin{aligned}
G_{*}(d, q)= & I\left[\eta-i_{*}(d)\right]\left[r_{*}^{c}(d)-r_{*}^{d}(d)\right]+d\left(1+r_{*}^{d}(d)\right) \\
& -\frac{1}{2} q f(e+I)\left[i_{B}\left(i_{*}(d), r_{*}^{c}(d), q\right)-i_{*}(d)\right]^{2}
\end{aligned}
$$


whenever $q>q_{\mathrm{TB}}\left(r_{*}^{c}(d)\right)$. In this case $i_{B}\left(i_{*}(d), r_{*}^{c}(d), q\right)<\eta$ and there are entrepreneurs who repay their loans fully. Eq. (17) reflects the fact that risk premia serve as a buffer against losses due to bankruptcies, which occur as soon as $i_{B}\left(i_{*}(d), r_{*}^{c}(d), q\right)$ $>i_{*}(d)$. If risk premia become too small, large losses may cause a default of the banking system.

We will show next that risk premia will become arbitrarily small if the capital base of the banking system tends toward zero. Assuming that $q_{\mathrm{NB}}\left(i_{*}(d), r_{*}^{c}(d)\right)>\underline{q}$ for small $d$, the probability of bankruptcies of entrepreneurs is positive for small $d$. These defaults of entrepreneurs will be responsible for vanishing risk premia. Consider the case in which for $d \in(0, \bar{d}]$ sufficiently small, the productivity of entrepreneurs is sufficiently high, so that no entrepreneur enters bankruptcy with positive probability. Using the definition in (14), we see that this is the case if

$$
q_{\mathrm{NB}}\left(i_{*}(d), r_{*}^{c}(d)\right) \leq q_{\mathrm{NB}}\left(i_{G}\left(d, r_{\mathrm{UB}}^{d}\right), r_{\mathrm{UB}}^{c}\right)<\bar{q} \text { for sufficiently small } d>0
$$

We are now in a position to state the following proposition.

\section{Theorem 2}

Under the hypotheses of Theorem 1, let $q_{N B}\left(i_{G}\left(0, r_{U B}^{d}\right), r_{U B}^{c}\right)<\bar{q}$. Then the risk premia will vanish with a vanishing capital base, that is,

$$
\lim _{d \rightarrow 0}\left[r_{*}^{c}(d)-r_{*}^{d}(d)\right]=0
$$

Theorem 2 has important implications. If a banking system has lost most of its capital, the risk premia decline and hence the risk of a further decline of bank capital rises. At the limit where bank capital approaches zero, the risk premium vanishes. In order to explain this result, we observe that for a small level of bank capital a positive premium implies a very large return on equity ex post if the macroeconomic shock turns out to be sufficiently favorable. In such circumstances, banks earn more from the vast majority of loans than the deposit rate. As equity is small in relation to deposits and loans, return on equity becomes very large. Since negative shocks imply zero equity, a small risk premium is sufficient to generate the ex ante return on equity demanded by shareholders. 


\section{Default of the banking system}

In this section we investigate the possibility of a default of the banking system. We will show that the probability for a default of the banking system is positive if the capital base is below a certain threshold, which will be denoted by $d_{\text {crit }}$. This result is a consequence of the fact that risk premia may become arbitrarily small, as shown in Theorem 2. If a bank's capital base is too low, then banks will be unable to cover losses from bankruptcies of entrepreneurs. To formulate our next result, recall that bankruptcies of entrepreneurs occur with positive probability for all $d \in(0, \bar{d}]$, if $q_{\mathrm{NB}}\left(i_{G}(0,0), r_{\mathrm{LB}}^{c}\right)>\underline{q}$.

\section{Proposition 2}

Under the hypotheses of Theorem 1, suppose that $q_{N B}\left(i_{G}(0,0), r_{L B}^{c}\right)>\underline{q}$. Then there exists a critical capital level $d_{c r i t} \in(0, \bar{d}]$ such that the banking system defaults with positive probability, that is,

$$
\mathbb{P}\left(G_{*}(d, \cdot)<0\right)>0 \quad \text { whenever } d<d_{\text {crit }} .
$$

The proof of Proposition 2 is to be found in the appendix. The underlying economic forces at work in Proposition 2 can be described as follows. A level of bank capital below $d_{\text {crit }}$ makes the banking system vulnerable to default in two ways. First, the buffer against defaults of entrepreneurs is small. Second, the risk premium is small, and even intermediate macroeconomic shocks may lead to a decline of bank capital.

We will show next that the banking system will default in finite time with probability one. Again, if the productivity of entrepreneurs is so low that $G_{*}(\bar{d}, q)<0$ for shocks $q \leq q_{\mathrm{TB}}\left(r_{\mathrm{LB}}^{c}\right)$, then the monotonicity of the maps $d \mapsto G_{*}(d, q), q \leq q_{\mathrm{TB}}\left(r_{\mathrm{LB}}^{c}\right)$ implies an immediate bankruptcy of the banking system as soon as the event $q \leq q_{\mathrm{TB}}\left(r_{\mathrm{LB}}^{c}\right)$ occurs. We therefore assume in the following that $G_{*}(\bar{d}, \underline{q})>0$, such that a sufficiently high capital base will insure against bankruptcies of banks.

The argument is based upon the following line of reasoning. We will show that there exists a critical shock $q_{\text {crit }}>\underline{q}$ such that the capital base will decrease for shocks below $q_{\text {crit }}$, i.e.,

$$
G_{*}(d, q)<d \quad \text { for all } d \in(0, \bar{d}], q \leq q_{\text {crit }} .
$$


Then a series of sufficiently many shocks $q_{t}, \ldots, q_{t+\tau}$ below $q_{\text {crit }}$ will lead to a series of decreasing capital bases

$$
d_{t+1}=G_{*}\left(d_{t}, q_{t}\right)>\cdots>d_{t+1+\tau}=G_{*}\left(d_{t+\tau}, q_{t+\tau}\right)
$$

that will finally take on a value below zero, thus causing a default of the banking system. Let $T_{0}$ denote the first time for which the capital base of the banking system has vanished and the system has accumulated losses, that is, the first time for which $d_{T_{0}}<0$. In the next proposition we will show that the event $T_{0}<\infty$ occurs with probability one, implying that the banking system will default in finite time with probability one.

\section{Theorem 3}

Under the hypotheses of Theorem 1, let $q_{N B}\left(i_{G}(0,0), r_{L B}^{c}\right)>\underline{q}$ and suppose that

$$
\frac{P\left(i_{G}(0,0), q, r_{U B}^{c}\right)}{I\left[\eta-i_{G}(0,0)\right]}<1+\frac{S\left(r_{*}^{d}(\bar{d})\right)}{I \eta} r_{*}^{d}(\bar{d}) \quad \text { for all } q \leq q_{N B}\left(i_{G}(0,0), r_{L B}^{c}\right) .
$$

Then for an arbitrary initial capital level $d_{0} \in(0, \bar{d}]$ the banking system will default in finite time with probability one, that is, $\mathbb{P}\left(T_{0}<\infty\right)=1$.

The proof of Theorem 3 is given in the appendix. Theorem 3 implies that a banking system cannot protect itself from a default which will occur with certainty if the return on debt $P\left(i_{G}(0,0), q, r_{\mathrm{UB}}^{c}\right) /\left(I\left[\eta-i_{G}(0,0)\right]\right)$ is too low. In this case a vicious circle starts. Repeated negative macroeconomic shocks lower the equity of banks until it ultimately lies below the critical level $d_{c r i t}$. Further negative macroeconomic shocks then lead to a downward spiral of bank capital. As equity declines, the risk premium decreases, which in turn increases the probability of further declines in bank capital. Over time the banking system will default. 


\section{Discussion and Conclusion}

The results of the present paper suggest that vulnerabilities of a banking system may build up over time while at the same time risk premia decline. This creates the danger of large-scale defaults of banks. Apart from the policy implications outlined in the introduction, we hope that the current framework offers avenues for further research which are briefly outlined in this section.

Our analysis rests on symmetric information for all market participants. In recent proposals to revise the 1988 accord on bank capital adequacy, regulators have placed great emphasis on the disclosures by banks in order to allow market discipline to operate effectively (Basel Committee on Banking Supervision 1999). In order to examine the role of public information models with private and public signals about repayment risks across banks in the spirit of Hellwig (2000), Morris \& Shin (2002, 2004) and Shin (2003) could be combined with the model in this paper. Since public information conveys information about fundamentals as well as can serve as a focal point for beliefs (see Morris \& Shin (2004)), the effect of public information on risk premia in banking is likely to be ambiguous. How public information in such a context would affect the default risk of banks is therefore an open question.

Moreover, one could allow for international financial markets following Matsuyama (2002, 2004). He has shown that financial market globalization may be symmetrybreaking and introduce endogenous components of heterogeneities across countries. Combining these insights with the current model may offer an approach that can explain why banking crises are so prevalent in poor countries.

At another level, one might ask whether it is possible to improve the protection of banks from macroeconomic risks. How securities, deposit, and loan contracts might be designed to reduce macroeconomic risks on the balance sheets of banks appears to be one of the most important research issues in the light of the present findings. 


\section{A Appendix}

Before listing the main proofs, we present the following result.

\section{Proposition 3}

Let $r^{c} \geq 0$ be arbitrary. Then for each $q \in \mathbb{R}_{+}$, the average repayment per unit of loan $P\left(i, q, r^{c}\right) /([\eta-i] I)$ is non-decreasing in quality levels $i \in[0, \eta]$.

\section{Proof .}

Let $i_{1}<i_{0} \in[0, \eta]$ and $q \in \mathbb{R}_{+}$be arbitrary but fixed. According to the mean value theorem there exists $j_{0} \in\left[i_{0}, \eta\right]$ with

$$
\left.\frac{P\left(i_{0}, q, r^{c}\right)}{\left[\eta-i_{0}\right] I}=\min \left\{\left(1+j_{0}\right) q f(e+I) / I, 1+r^{c}\right)\right\}
$$

Moreover, it is straightforward to verify

$$
\left.P\left(i_{1}, q, r^{c}\right) \leq\left[\eta-i_{1}\right] \min \left\{\left(1+j_{0}\right) q f(e+I) / I, 1+r^{c}\right)\right\}
$$

Then (18) and (19) imply

$$
\left.\frac{P\left(i_{1}, q, r^{c}\right)}{\left[\eta-i_{1}\right] I} \leq \min \left\{\left(1+j_{0}\right) q f(e+I) / I, 1+r^{c}\right)\right\}=\frac{P\left(i_{0}, q, r^{c}\right)}{\left[\eta-i_{0}\right] I} .
$$

Since $i_{1}<i_{0}$ were arbitrary, this completes the proof.

\section{Proof of Theorem 1.}

We will show that for each $d \in(0, \bar{d}]$ the two equilibrium conditions (6) and (7) define curves in the $r^{d}-r^{c}$ plane whose unique intersection point is the TEFI.

Step 1. Let $d \in(0, \bar{d}]$ and $r^{d} \in\left[0, \bar{r}^{d}\right]$ be arbitrary but fixed, and consider first the no-entry condition (6). Since

$$
P\left(i_{G}\left(d, r^{d}\right), q, r^{d}\right) \leq I\left[\eta-i_{G}\left(d, r^{d}\right)\right]\left(1+r^{d}\right),
$$

for all shocks $q$, it follows from (3) that

$$
\mathbb{E}\left[G^{+}\left(d, \cdot, r^{d}, r^{d}\right)\right] \leq d\left(1+r^{d}\right)
$$


Set

$$
\bar{r}^{c}:=\frac{(1+\eta) \bar{q} f(e+I)}{I}-1
$$

and notice that by Assumption (i), $\bar{r}^{c}>0$. It is straightforward to verify that

$$
\mathbb{E}\left[G^{+}\left(d, \cdot, r^{d}, \bar{r}^{c}\right)\right] \geq \mathbb{E}\left[G\left(d, \cdot, r^{d}, \bar{r}^{c}\right)\right]>d\left(1+r^{d}\right)
$$

and to verify that $\mathbb{E}\left[G^{+}\left(d, \cdot, r^{c}, r^{d}\right)\right]$ is increasing in $r^{c}$, for $r^{c} \leq \bar{r}^{c}$. The Intermediate Value Theorem then implies for each $d \in(0, \bar{d}]$ and each $r^{d} \in\left[0, \bar{r}^{d}\right]$ the existence of an interest rate $r^{c}=g\left(d, r^{d}\right) \geq r^{d}$ such that

$$
\mathbb{E}\left[G^{+}\left(d, \cdot, r^{d}, g\left(d, r^{d}\right)\right)\right]-d\left(1+r^{d}\right)=0
$$

Moreover, $g\left(d, r^{d}\right)$ is a continuous function of both arguments, where each $g(d, \cdot), d \in$ $(0, \bar{d}]$ describes a curve in the $r^{d}-r^{c}$ plane.

The the no-entry condition (6) is equivalent to

$$
\mathbb{E}\left[\max \left\{\frac{P\left(i_{G}\left(d, r^{d}\right), \cdot, r^{c}\right)}{I\left[\eta-i_{G}\left(d, r^{d}\right)\right]}-\left(1+r^{d}\right), \frac{-d\left(1+r^{d}\right)}{I\left[\eta-i_{G}\left(d, r^{d}\right)\right]}\right\}\right] \stackrel{!}{=} 0 .
$$

By Proposition 3 and Assumption (ii), both functions in the max-operator are nonincreasing functions of $d$ and $r^{d}$. Hence $r^{c}=g\left(d, r^{d}\right)$ is non-decreasing in both $d$ and $r^{d}$.

Step 2. Consider now Condition (7) which takes the form

$$
\Pi\left(i_{G}\left(d, r^{d}\right), r^{c}\right)-e\left(1+r^{d}\right) \stackrel{!}{=} 0, \quad d \in(0, \bar{d}]
$$

By Assumption (i), for each $d \in(0, \bar{d}], r^{d} \in\left[0, \bar{r}^{d}\right]$,

$$
\Pi\left(i_{G}\left(d, r^{d}\right), 0\right) \geq \Pi(0,0)>e\left(1+\bar{r}^{d}\right) \geq e\left(1+r^{d}\right)
$$

Note that this condition holds including $d=0$. On the other hand, for each $i \in[0, \eta]$, $\Pi\left(i, \bar{r}^{c}\right)=0$ and $\Pi\left(i, r^{c}\right)$ is strictly decreasing for $r^{c} \leq \bar{r}^{c}$. Thus, for each $d \in[0, \bar{d}]$, $r^{d} \in\left[0, \bar{r}^{d}\right]$, there exists a continuous function $r^{c}=h\left(d, r^{d}\right)$ solving (25). Moreover, for each $d \in[0, \bar{d}], r^{d} \mapsto h\left(d, r^{d}\right)$ is a curve in the $r^{d}-r^{c}$ plane. Since $\Pi\left(i, r^{c}\right)$ is strictly increasing in $i$ and $i_{G}\left(d, r^{d}\right)$ is strictly decreasing in $d$ and $r^{d}, h\left(d, r^{d}\right)$ must be strictly decreasing in $d$ and $r^{d}$. 
Step 3. We show next that for each $d \in(0, \bar{d}]$, the curve $h(d, \cdot)$ defined in $(25)$ and the curve $g(d, \cdot)$ defined in (24) have a unique intersection point $\left(r_{*}^{d}(d), r_{*}^{c}(d)\right)$ which satisfies

$$
h\left(d, r_{*}^{d}(d)\right)=g\left(d, r_{*}^{d}(d)\right)=r_{*}^{c}(d)
$$

and thus is the uniquely determined TEFI. Uniqueness of $\left(r_{*}^{d}(d), r_{*}^{c}(d)\right)$ follows from the strict monotonicity of each $h(d, \cdot)$, so that we are left to prove existence.

Setting $d=\bar{d}$ and $r^{d}=0,(24)$ together with Proposition 3 imply

$$
\mathbb{E}\left[\frac{P\left(i_{G}(\bar{d}, 0), \cdot g(\bar{d}, 0)\right)}{I\left[\eta-i_{G}(\bar{d}, 0)\right]}-1\right] \geq \frac{\mathbb{E}\left[P\left(0, \cdot, r_{0}^{c}\right)\right]}{\eta I}-1 \geq 0
$$

It follows from Assumption (iii) that

$$
r_{0}^{c} \geq g(\bar{d}, 0)
$$

On the other hand, we have

$$
\Pi\left(i_{G}(\bar{d}, 0), h(\bar{d}, 0)\right)=e=\Pi\left(0, r_{0}^{c}\right)
$$

and since $i_{G}(\bar{d}, 0) \geq 0$, the monotonicity of $\Pi\left(i, r^{c}\right)$ implies $h(\bar{d}, 0) \geq r_{0}^{c}$. The monotonicity properties of $g$ and $h$ then yield

$$
h(d, 0) \geq h(\bar{d}, 0) \geq r_{0}^{c} \geq g(\bar{d}, 0) \geq g(d, 0) .
$$

By Assumption (i) we have

$$
\Pi\left(i_{G}(0,0), 0\right) \geq \Pi(0,0)>e \quad \text { and } \quad \Pi\left(i_{G}\left(0, \bar{r}^{d}\right), \bar{r}^{d}\right) \leq \Pi\left(\eta, \bar{r}^{d}\right)<e\left(1+\bar{r}^{d}\right) .
$$

As a consequence, there exists a unique $r_{0}^{d} \in\left(0, \bar{r}^{d}\right)$ such that

$$
\Pi\left(i_{G}\left(0, r_{0}^{d}\right), r_{0}^{d}\right)=e\left(1+r_{0}^{d}\right)
$$

Hence $h\left(0, r_{0}^{d}\right)=r_{0}^{d}$ and since $h\left(0, r^{d}\right)$ is decreasing in $r^{d}, h\left(0, \bar{r}^{d}\right)<\bar{r}^{d}$. The monotonicity properties of $g$ and $h$ then imply

$$
h\left(d, \bar{r}^{d}\right) \leq h\left(0, \bar{r}^{d}\right)<\bar{r}^{d} \leq g\left(d, \bar{r}^{d}\right)
$$

The existence of the desired intersection point now follows from (27) and (29) and the Intermediate Value Theorem. 
Step 4. We will show finally that $\left(r_{*}^{d}(d), r_{*}^{c}(d)\right) \in\left[0, r_{\mathrm{UB}}^{d}\right] \times\left[r_{\mathrm{LB}}^{c}, r_{\mathrm{UB}}^{c}\right]$. First of all, since $g\left(d, r^{d}\right) \geq r^{d} \geq 0$, risk premia must be non-negative so that $r_{*}^{c}(d) \geq r_{*}^{d}(d) \geq 0$. For the same reason, $r_{*}^{d}(d) \leq r_{0}^{d}$, where $r_{0}^{d}$ was given in $(28)$. Since $i_{G}\left(0, r_{0}^{d}\right) \leq \eta$,

$$
e\left(1+r_{0}^{d}\right)=\Pi\left(i_{G}\left(0, r_{0}^{d}\right), r_{0}^{d}\right) \leq \Pi\left(\eta, r_{0}^{d}\right)
$$

It follows from the definition of $r_{\mathrm{UB}}^{d}$ and the monotonicity of $\Pi\left(i, r^{c}\right)$ with respect to the second argument that $r_{0}^{d} \leq r_{\mathrm{UB}}^{d}$. This implies $r_{*}^{d}(d) \in\left[0, r_{\mathrm{UB}}^{d}\right]$ for all $d \in(0, \bar{d}]$.

Since

$$
\Pi\left(i_{G}(0,0), h(0,0)\right)=e=\Pi\left(\eta, r_{\mathrm{UB}}^{c}\right)
$$

and $i_{G}(0,0) \leq \eta$, an upper bound for each $r_{*}^{c}(d), d \in(0, \bar{d}]$ is

$$
r_{*}^{c}(d)=h\left(d, r_{*}^{d}(d)\right) \leq h(0,0) \leq r_{\mathrm{UB}}^{c}
$$

On the other hand, analogous to $(28)$ there exists a unique $\bar{r}_{0}^{d} \in\left(0, \bar{r}^{d}\right)$ such that

$$
\Pi\left(i_{G}\left(\bar{d}, \bar{r}_{0}^{d}\right), h\left(\bar{d}, \bar{r}_{0}^{d}\right)\right)=e\left(1+\bar{r}_{0}^{d}\right)
$$

Since $i_{G}\left(\bar{d}, \bar{r}_{0}^{d}\right) \geq 0$, we have $\Pi\left(0, \bar{r}_{0}^{d}\right) \leq e\left(1+\bar{r}_{0}^{d}\right)$. It follows from the definition of $r_{\mathrm{LB}}^{c}$ and the monotonicity of $\Pi\left(i, r^{c}\right)$ with respect to the second argument that $\bar{r}_{0}^{d} \geq r_{\mathrm{LB}}^{c}$. This implies that $r_{\mathrm{LB}}^{c}$ is a lower bound each $r_{*}^{c}(d), d \in(0, \bar{d}]$.

\section{Proof of Corollary 1.}

As shown in the proof of Proposition $1, g\left(d, r^{d}\right) \geq r^{d}$ for all $d \in(0, \bar{d}]$ and all $r^{d} \in\left[0, \bar{r}^{d}\right]$, such that $r_{*}^{c}(d)-r_{*}^{d}(d) \geq 0$ for each $d \in(0, \bar{d}]$. Since $g\left(d, r^{d}\right)$ as defined by (23) is nondecreasing in $d$ and $r^{d}$ and $h\left(d, r^{d}\right)$ as defined by (25) is strictly decreasing in $d$ and $r^{d}$, the equilibrium deposit rate $r_{*}^{d}(d)$ is decreasing in $d$.

\section{Proof of Lemma 1.}

The proof of Lemma 1 follows the lines of the proof of Proposition 1, only Condition (6) has to be replaced by Condition (9). 
Step 1. Let $d \in(0, \bar{d}]$ and $r^{d} \in\left[0, \bar{r}^{d}\right]$ be arbitrary but fixed. Clearly, $\mathbb{E}\left[G\left(d, \cdot, r^{d}, \bar{r}^{c}\right)\right]$ is increasing for $r^{c} \leq \bar{r}^{c}$ with $\bar{r}^{c}$ defined by (21). Conditions (20) and (22) then imply the existence of a continuous function

$$
\tilde{g}:(0, \bar{d}] \times\left[0, \bar{r}^{d}\right] \rightarrow \mathbb{R}_{+}
$$

such that

$$
\mathbb{E}\left[G\left(d, \cdot, r^{d}, \tilde{g}\left(d, r^{d}\right)\right)\right]-d\left(1+r^{d}\right)=0
$$

for all $d \in(0, \bar{d}]$ and $r^{d} \in\left[0, \bar{r}^{d}\right]$. Since

$$
\mathbb{E}\left[G\left(d, \cdot, r^{d}, r^{c}\right)\right] \leq \mathbb{E}\left[G^{+}\left(d, \cdot, r^{d}, r^{c}\right)\right]
$$

it follows from (23) and (30) that

$$
\tilde{g}\left(d, r^{d}\right) \geq g\left(d, r^{d}\right) \geq r^{d}, \quad d \in(0, \bar{d}], r^{d} \in\left[0, \bar{r}^{d}\right]
$$

Step 2. As in Theorem 1, a temporary equilibrium with intermediation under full liability is given by an intersection point of the two curves $\tilde{g}(d, \cdot)$ and $h(d, \cdot)$, where the latter was defined in (25). Analogous to Step 3 in the proof of Theorem 1, Assumption (iii) in Theorem 1 together with the monotonicity properties of $h$ and $\tilde{g}$ imply

$$
h(d, 0) \geq h(\bar{d}, 0) \geq r_{0}^{c} \geq \tilde{g}(\bar{d}, 0) \geq \tilde{g}(d, 0)
$$

for all $d \in(0, \bar{d}]$. As before,

$$
h\left(d, \bar{r}^{d}\right) \leq h\left(0, \bar{r}^{d}\right)<\bar{r}^{d} \leq \tilde{g}\left(d, \bar{r}^{d}\right)
$$

for all $d \in(0, \bar{d}], r^{d} \in\left[0, \bar{r}^{d}\right]$. For each $d \in(0, \bar{d}]$, the existence and uniqueness of the desired intersection point

$$
\left(r_{+}^{d}(d), r_{+}^{c}(d)\right) \in\left[0, r_{\mathrm{UB}}^{d}\right] \times\left[r_{\mathrm{LB}}^{c}, r_{\mathrm{UB}}^{c}\right]
$$

now follows from (32), (33), the Intermediate Value Theorem and the corresponding inequalities in Step 4 of the proof of Theorem 1.

Step 3. Inequality (31) implies the assertion of the lemma. 


\section{Proof of Proposition 1.}

(i) If there is zero probability for bankruptcies of entrepreneurs, then

$$
G_{*}(d, q)=I\left[\eta-i_{*}(d)\right]\left[r_{*}^{c}(d)-r_{*}^{d}(d)\right]+d\left(1+r_{*}^{d}(d)\right) \geq 0
$$

for all $d \in(0, \bar{d}]$ and all $q \in[\underline{q}, \bar{q}]$. This implies

$$
\mathbb{E}\left[G_{*}^{+}(d, \cdot)\right]=I\left[\eta-i_{*}(d)\right]\left[r_{*}^{c}(d)-r_{*}^{d}(d)\right]+d\left(1+r_{*}^{d}(d)\right)
$$

and the equilibrium condition (7) shows that the risk premia must be zero and $r_{*}^{c}(d)=$ $r_{*}^{d}(d)$.

(ii) Suppose, on the contrary, that risk premia were zero such that $r_{*}^{c}(d)=r_{*}^{d}(d)$. Since bankruptcies occur with positive probability, for each $q<q_{\mathrm{NB}}\left(i_{*}(d), r_{*}^{c}(d)\right)$,

$$
P\left(i_{*}(d), q, r_{*}^{d}(d)\right)<I\left[\eta-i_{*}(d)\right]\left(1+r_{*}^{d}(d)\right)
$$

and thus

$$
\begin{aligned}
G_{*}(d, q) & =P\left(i_{*}(d), q, r_{*}^{d}(d)\right)-\left[I\left[\eta-i_{*}(d)\right]-d\right]\left(1+r_{*}^{d}(d)\right) \\
& <d\left(1+r_{*}^{d}(d)\right) .
\end{aligned}
$$

This implies

$$
\begin{aligned}
\mathbb{E}\left[G_{*}^{+}(d, \cdot)\right]= & \int_{q_{\mathrm{NB}}\left(i_{*}(d), r_{*}^{d}(d)\right)}^{\bar{q}} d\left(1+r_{*}^{d}(d)\right) \mu(d q) \\
& \quad+\int_{\underline{q}}^{q_{\mathrm{NB}}\left(i_{*}(d), r_{*}^{d}(d)\right)} G^{+}\left(d, \cdot r_{*}^{d}(d), r_{*}^{d}(d)\right) \mu(d q) \\
& <d\left(1+r_{*}^{d}(d)\right),
\end{aligned}
$$

thus contradicting the equilibrium condition $(7)$. Hence $r_{*}^{c}(d)>r_{*}^{d}(d)$.

\section{Proof of Theorem 2.}

Given the equilibrium interest rates $\left(r_{*}^{d}(d), r_{*}^{c}(d)\right)$, the no-entry condition $(6)$ takes the form

$$
\mathbb{E}\left[G^{+}\left(d, \cdot, r_{*}^{c}(d), r_{*}^{d}(d)\right)\right]=d\left(1+r_{*}^{d}(d)\right)
$$


Since $r_{*}^{d}(d)$ is bounded for all $d \in(0, \bar{d}]$, the r.h.s. of (34) converges to zero if $d$ tends towards zero. Assume now that the assertion of the proposition is false. In this case there must exist a small number $\delta>0$ such that

$$
\left[r_{*}^{c}(d)-r_{*}^{d}(d)\right] \geq \delta>0 \quad \text { for all sufficiently small } d>0
$$

For shocks $q \geq q_{\mathrm{NB}}\left(i_{*}(d), r_{*}^{c}(d)\right)$, one has

$$
G_{*}(d, q)=I\left[\eta-i_{*}(d)\right]\left[r_{*}^{c}(d)-r_{*}^{d}(d)\right]+d\left(1+r_{*}^{d}(d)\right) \geq I\left[\eta-i_{*}(d)\right] \delta .
$$

Since $q_{\mathrm{NB}}\left(i_{G}\left(0, r_{\mathrm{UB}}^{d}\right), r_{\mathrm{UB}}^{c}\right)<\bar{q}$, we have $q_{\mathrm{NB}}\left(i_{*}(d), r_{*}^{c}(d)\right)<\bar{q}$ for all sufficiently small d. As a consequence, the l.h.s. of (34) satisfies

$$
\mathbb{E}\left[G^{+}\left(d, \cdot, r_{*}^{c}(d), r_{*}^{d}(d)\right)\right] \geq \int_{q_{\mathrm{NB}}\left(i_{*}(d), r_{*}^{c}(d)\right)}^{\bar{q}} \mu(d q)\left(I\left[\eta-i_{*}(d)\right] \delta\right)>0
$$

for all sufficiently small $d>0$. Therefore, the equilibrium condition (34) is violated for all sufficiently small $d>0$, which contradicts the initial presumption (35).

\section{Proof Proposition 2.}

Observe first that the definition of $G_{*}$ and (5) imply that for each $d \in(0, \bar{d}]$,

$$
G_{*}(d, q)<G_{*}\left(d, q^{\prime}\right) \quad \text { whenever } q<q^{\prime} \leq q_{\mathrm{NB}}\left(i_{G}(0,0), r_{\mathrm{LB}}^{c}\right)
$$

Moreover, it is straightforward to verify that for each $q \leq q_{\mathrm{TB}}\left(r_{\mathrm{LB}}^{c}\right)$, the map

$$
G_{*}(\cdot, q):(0, \bar{d}] \rightarrow \mathbb{R}, \quad d \mapsto G_{*}(d, q)
$$

is monotonically increasing. Therefore, if $G_{*}(\bar{d}, \underline{q})<0$, then the proposition holds trivially for $d_{\text {crit }}:=\bar{d}$.

Assume now that $G_{*}(\bar{d}, \underline{q}) \geq 0$. The evolution of the capital base is driven by the map

$$
\begin{aligned}
G_{*}(d, q)=I[ & \left.\eta-i_{*}(d)\right]\left[r_{*}^{c}(d)-r_{*}^{d}(d)\right]+d\left(1+r_{*}^{d}(d)\right) \\
& -\frac{1}{2} q f(e+I)\left[i_{B}\left(i_{*}(d), r_{*}^{c}(d), q\right)-i_{*}(d)\right]^{2}
\end{aligned}
$$

provided that $i_{B}\left(i_{*}(d), r_{*}^{c}(d), q\right)<\eta$. For $q \geq q_{\mathrm{NB}}\left(i_{G}\left(\bar{d}, r_{\mathrm{UB}}^{d}\right), r_{\mathrm{UB}}^{c}\right)$, we have

$$
G_{*}(d, q)=I\left[\eta-i_{*}(d)\right]\left[r_{*}^{c}(d)-r_{*}^{d}(d)\right]+d\left(1+r_{*}^{d}(d)\right) \geq 0, \quad d \in(0, \bar{d}] .
$$


Using Theorem 2 and the boundedness of the equilibrium interest rates, it follows that

$$
\lim _{d \rightarrow 0} G_{*}(d, q)=0 \quad \text { for all } q \geq q_{\mathrm{NB}}\left(i_{G}\left(\bar{d}, r_{\mathrm{UB}}^{d}\right), r_{\mathrm{UB}}^{c}\right)
$$

On the other hand, for each sufficiently low shock, i.e. for $\underline{q} \leq q<q_{\mathrm{NB}}\left(i_{G}(0,0), r_{\mathrm{LB}}^{c}\right)$, we have

$$
i_{B}\left(i_{*}(d), r_{*}^{c}(d), q\right)>i_{*}(d) \text { for all } d \in(0, \bar{d}]
$$

implying that

$$
\lim _{d \rightarrow 0} G_{*}(d, q)<0 \quad \text { at least for } \underline{q} \leq q<q_{\mathrm{NB}}\left(i_{G}(0,0), r_{\mathrm{LB}}^{c}\right) .
$$

It follows from the continuity of the map $G_{*}$ and (37) that there exists a unique $d_{\text {crit }} \in$ $(0, \bar{d}]$ with $G_{*}\left(d_{\text {crit }}, \underline{q}\right)=d_{\text {crit }}$. The monotonicity property $(36)$ shows that $G_{*}(d, q)<0$ for all $d<d_{\text {crit }}$ and all sufficiently low shocks $q$. This proves the proposition.

\section{Proof Theorem 3.}

Let $d \in(0, \bar{d}]$ be arbitrary and recall $i_{*}(d)=i_{G}\left(d, r_{*}^{d}(d)\right)$. It is straightforward to see that $G_{*}(d, q)<d$ is equivalent to

$$
\frac{P\left(i_{*}(d), q, r_{*}^{c}(d)\right)}{I\left[\eta-i_{*}(d)\right]}<1+\left(\frac{S\left(r_{*}^{d}(d)\right)+e i_{*}(d)}{I\left[\eta-i_{*}(d)\right]}\right) r_{*}^{d}(d) .
$$

By Theorem 1, the r.h.s. of (38) is bounded from below by

$$
1+\frac{S\left(r_{*}^{d}(\bar{d})\right)}{I \eta} r_{*}^{d}(\bar{d})
$$

Since $i_{G}\left(d, r^{d}\right)$ is decreasing in $d$ and $r^{d}$, by Proposition 3, the l.h.s. of (38) is bounded from above by

$$
\frac{P\left(i_{G}(0,0), q, r_{\mathrm{UB}}^{c}\right)}{I\left[\eta-i_{G}(0,0)\right]}
$$

Thus (38) holds for all $d \in(0, \bar{d}]$ and all $\underline{q} \leq q \leq q_{\mathrm{NB}}\left(i_{G}(0,0), r_{\mathrm{LB}}^{c}\right)$ showing that

$$
G_{*}(d, q)<d \quad \text { for all } d \in(0, \bar{d}], \underline{q} \leq q \leq q_{\mathrm{NB}}\left(i_{G}(0,0), r_{\mathrm{LB}}^{c}\right)
$$

As in the proof of Proposition 2, there exists $d_{\text {crit }} \in(0, \bar{d}]$, defined by

$$
G_{*}\left(d_{\mathrm{crit}}, q_{\mathrm{NB}}\left(i_{G}(0,0), r_{\mathrm{LB}}^{c}\right)\right)=d_{\mathrm{crit}}
$$


such that

$$
G_{*}(d, q)<0 \text { for all } d<d_{\text {crit }}, q \leq q_{\mathrm{NB}}\left(i_{G}(0,0), r_{\mathrm{LB}}^{c}\right) .
$$

For $\tilde{d}_{0}=\bar{d}$, define recursively

$$
\tilde{d}_{t+1}:=G_{*}\left(\tilde{d}_{t}, q_{\mathrm{NB}}\left(i_{G}(0,0), r_{\mathrm{LB}}^{c}\right)\right), \quad t=0,1,2, \ldots
$$

Equations (39) and (40) imply that there exists a natural number $\tau>0$ such that $\tilde{d}_{\tau+1}<0$. This observation shows that for arbitrary $d_{t_{0}} \in(0, \bar{d}]$ in an arbitrary period $t_{0}$, a series of at most $\tau$ shocks $q_{t_{0}}, \ldots, q_{t_{0}+\tau} \leq q_{\mathrm{NB}}\left(i_{G}(0,0), r_{\mathrm{LB}}^{c}\right)$ will lead to the event $d_{t_{0}+\tau+1}<0$, where

$$
d_{t+1}=G_{*}\left(d_{t}, q_{t}\right), \quad t=t_{0}, \ldots, t_{0}+\tau
$$

Since the shock process $\left\{q_{t}\right\}_{t \in \mathbb{N}}$ is ergodic, the event

$$
q_{t_{0}}, \ldots, q_{t_{0}+\tau} \leq q_{\mathrm{NB}}\left(i_{G}(0,0), r_{\mathrm{LB}}^{c}\right), \quad t_{0}<\infty
$$

will occur with probability one. Setting $T_{0}=t_{0}+\tau$, this proves the theorem. 


\section{References}

Alos-Ferrer, C. (1999): "Individual Randomness in Economic Models with a Continuum of Agents", Working Paper, N0. 9807, Department of Economics, University of Vienna.

Basel Committee on Banking Supervision(1999): "Recommendations for Public Disclosure of Trading and Derivatives Activities of Banks and Securities Firms". Basel: Bank for International Settlements.

BAueR, H. (1991): Wahrscheinlichkeitstheorie. de Gruyter, Berlin a.o.

Bernanke, B. (1983): "Non-Monetary Effects of the Financial Crisis in the Propagation of the Great Depression", American Economic Review, 73(3), 257-276.

Bernanke, B. \& M. Gertler (1983): "Agency Costs, Net Worth, and Business Fluctuations", American Economic Review, 79(1), 14-31.

Bhattacharya, S., A. Boot \& A. V. Thakor (1998): "The Economics of Bank Regulation", Journal of Money Credit and Banking, 30(4), 745-770.

Bhattacharya, S. \& A. V. Thakor (1993): "Contemporary Banking Theory", Journal of Financial Intermediation, 3, 2-50.

Blum, J. \& M. F. Hellwig (1995): "The Macroeconomic Implications of Capital Adequacy Requirements", European Economic Review, 39, 733-749.

Borio, C. (2003): "A Framework for Financial Supervision and Regulation", CESifo Economics Studies, 49 (2), 181-215.

Caballero, R. \& K. Krishnamurthy (1998): "Emerging Markets Crises: An Asset Markets Perspective", Discussion paper, NBER Working paper No. 6843.

Caprio, G. \& P. Honohan (1999): "Restoring Banking Stability: Beyond Supervised Capital Requirements", Journal of Economic Perspectives, 13(4), 43-64.

Caprio, G. \& D. Klingebiel (1997): "Bank Insolvency: Bad Luck, Bad Policy or Bad Banking?", in World Bank Annual Conference on Development Economics, 1996, ed. by M. Bruno \& B. Pleskovic. 
Chang, R. \& A. Velasco (1998): "Financial Crises in Emerging Markets: A Canonical Model", Working paper no. 6606, National Bureau of Economic Research.

Dewatripont, M. \& J. Tirole (1994): The Prudential Regulation of Banks. MIT Press.

Freixas, X. \& J.-C. Rochet (1997): Microeconomics of Banking. MIT Press, Cambridge, MA.

Gersbach, H. \& J. Wenzelburger (2001): "The Dynamics of Deposit Insurance and the Consumption Trap", Discussion Paper No. 343, University of Heidelberg, Germany, and CESifo Working Paper No. 509, Munich.

(2003): "The Workout of Banking Crises: A Macroeconomic Perspective", CESifo Economic Studies, 49(2), 233-258.

Gersbach, H. \& H. Uhlig (2004): "Debt Contracts and Collapse as Competition Phenomena", Journal of Financial Interemediation, forthcoming.

Greenwald, B. \& J. Stiglitz (1993): "Financial Market Imperfections and Business Cycles", Quarterly Journal of Economics, 108, 77-114.

Hellwig, M. F. (1994): "Banking and Finance at the End of the Twentieth Century", WWZ-Discussion paper no. 9426, University of Basel.

(1998): "Banks, Markets, and the Allocation of Risks", Journal of Institutional and Theoretical Economics, 154, 328-345.

Hellwig, C. (2000): "Public Information and the Multiplicity of Equilibria in Coordination Games", Working Paper, London School of Economics.

Kaminsky, G. L. \& C. M. Reinhart (1998): "The Twin Crises: The causes of banking and balance-of-payments problems", http://www.puaf.umd.edu.

Kiyotaki, N. \& J. Moore (1997): "Credit Cycles", Journal of Political Economy, 105(1), 211-248.

Lindren, C.-J., G. Gracia \& M. SaAl (1996): "Bank Soundness and Macroeconomic Policy", Discussion paper, International Monetary Fund, Washington, D.C. 
Matsuyama, K. (2002): "Good and Bad Investments: An Inquiry into the Causes of Credit Cycles", Available at http://faculty.econ.nwu.edu/faculty/matsuyama/.

Matsuyama, K.(2004): "Financial Market Globalization, Symmetry-Breaking and Endogenous Inequality of Nations", Econometrica, 72(3), 853-884.

Mishkin, F. (1996): "Understanding Financial Crises: A Developing Country Perspective", Discussion paper, Annual World Bank.

Morris, S., H. S. SHIN (2002): "Social Value of Public Information", American Economic Review, 92(5), 1521-1534.

Morris, S., H.S. Shin (2004): "Coordination Risk and the Price of Debt". European Economic Review, 48(1), 133-153.

Rogoff, K. (1999): "International Institutions for Reducing Global Financial Instability", Journal of Economic Perspectives, 13(4), 21-42.

Sachs, J. D. \& S. RAdelet (1998): "The Onset of the East Asian Financial Crisis", Working paper, NBER.

SHIn, H.S. (2003): "Disclosures and Asset Returns", Econometrica, 71(1), 105-133.

Uhlig, H. (1995): "Transition and Financial Collapse", Discussion paper no. 66, CentER.

Uhlig, H. (1996): "A Law of Large Numbers for Large Economies", Economic Theory, 8, 41-50.

Williamson, S. D. (1987): "Financial Intermediation, Business Failures, and Real Business Cycles", Journal of Political Economy, 95, 1197-1216. 